\title{
Propagação in vitro e avaliação de parâmetros morfofisiológicos de porta-enxertos de videira ${ }^{(1)}$
}

\author{
Marcelo Borghezan(2), Liziane Kadine Antunes de Moraes $^{(3)}$, \\ Flávia Maia Moreira ${ }^{(4)}$ e Aparecido Lima da Silva ${ }^{(5)}$
}

\begin{abstract}
Resumo - A micropropagação de genótipos selecionados pode contribuir para atender a demanda de plantas matrizes e mudas de qualidade genética e sanitária comprovadas de videira (Vitis spp.) no Estado de Santa Catarina. O objetivo deste trabalho foi estabelecer e multiplicar in vitro porta-enxertos de videira e avaliar parâmetros morfofisiológicos fundamentais à micropropagação e aclimatização. Os porta-enxertos VR043-43, VR039-16, Paulsen 1103, R110, SO4 e Kober 5BB foram estabelecidos e multiplicados in vitro pelo método de gemas axilares em meio de cultura DSD1. Quarenta e dois por cento dos explantes foram estabelecidos in vitro. Houve variabilidade de crescimento, área foliar e matéria seca entre os genótipos. O porta-enxerto Paulsen 1103 foi numericamente superior aos demais no desenvolvimento in vitro em comprimento de caule $(6,2 \mathrm{~cm})$, produção de biomassa $(34,8 \mathrm{mg})$ e área foliar $\left(18,1 \mathrm{~cm}^{2}\right)$ in vitro. $\mathrm{O}$ teor de clorofila total variou entre os porta-enxertos e o ambiente de cultura, com 0,7 e $2,8 \mathrm{mg} / \mathrm{g}$ de matéria fresca do R110 (in vitro) e VR043-43 (ex vitro), respectivamente. A maior $\left(216,4 / \mathrm{mm}^{2}\right)$ e a menor $\left(119,2 / \mathrm{mm}^{2}\right)$ densidade estomática foram apresentadas pelo VR039-16 in vitro e pelo SO4 ex vitro, respectivamente. A taxa de sobrevivência de plantas na aclimatização foi em média $90,3 \pm 1,1 \%$ por genótipo. Os porta-enxertos de videira avaliados apresentaram características morfofisiológicas apropriadas para a propagação in vitro e a transferência ex vitro.
\end{abstract}

Termos para indexação: Vitis, micropropagação, biomassa, estômatos, clorofila.

\section{In vitro propagation and evaluation of morphophysiologic parameters of grapevine rootstocks}

Abstract - Micropropagation of selected genotypes can be valuable to achieve demand for elite plants with genetic fidelity and high sanitary quality of grapevine (Vitis spp.) in Santa Catarina State, Brazil. The objective of this work was to propagate grapevine rootstocks in vitro and to evaluate important morphophysiologic parameters for the plants micropropagation and acclimatization. Axillary buds of the rootstocks grapevine VR043-43, VR039-16, Paulsen 1103, R110, SO4 and Kober 5BB were inoculated in DSD1 culture medium. Rates of $42 \%$ of explants were established in vitro. There was variation in growth, leaf area and dry weight among the genotypes. Paulsen 1103 revealed superior features in vitro for length of the stem $(6.2 \mathrm{~cm})$, biomass production $(34.8 \mathrm{mg})$ and leaf area $\left(18.1 \mathrm{~cm}^{2}\right)$. The chlorophyll content showed variation among the rootstocks and the environment of the culture, ranging from 0.7 to $2.8 \mathrm{mg} / \mathrm{g}$ in fresh weight for R110 (in vitro) and VR043-43 (ex vitro), respectively. The highest $\left(216.4 / \mathrm{mm}^{2}\right)$ and the lowest $\left(119.2 / \mathrm{mm}^{2}\right)$ stomata number were shown by VR039-16 cultivated in vitro and by SO4 ex vitro, respectively. In the acclimatization stage, the mean of planting stock survival rate was $90.3 \pm 1.1 \%$ per genotype. The evaluated grapevine rootstocks present morphophysiologic parameters appropriated to in vitro propagation and ex vitro transference.

Index terms: Vitis, micropropagation, biomass, stomata, chlorophyll.

\footnotetext{
(1)Aceito para publicação em 23 de abril de 2003.

(2)Universidade Federal de Santa Catarina (UFSC), Caixa Postal 476, CEP 88040-900 Florianópolis, SC. Bolsista do PIBIC/CNPq. E-mail: mborghezan@hotmail.com

(3)UFSC, Bolsista do CNPq/RHAE.

E-mail:lizianekadine@yahoo.com.br

${ }^{(4)}$ Istituto Agrario di San Michele all'Adige (ISMAA), Via E. Mach, 38010 S. Michele all'Adige, Trento, Itália. E-mail: flavia.mmoreira@bol.com.br

${ }^{(5) U F S C, ~ D e p . ~ d e ~ F i t o t e c n i a . ~ E-m a i l: ~ a l s i l v a @ c c a . u f s c . b r ~}$
}

\section{Introdução}

A viticultura brasileira ocupa uma área superior a 63.800 hectares. Desse total, 2.233 ha estão no Estado de Santa Catarina, onde a viticultura caracteriza-se por ser uma atividade típica da agricultura familiar e, conseqüentemente, contribui para a fixação do homem no meio rural (Rosier \& Losso, 1997; Instituto de Planejamento e Economia Agrícola de Santa Catarina, 2001). 
Na década de 90, observou-se neste Estado uma queda considerável na produtividade dos vinhedos e uma forte redução da área plantada, decorrentes de viroses e morte de plantas, causadas pela fusariose (Fusarium oxysporum Sch. f.sp. herbemontis) e margarodes (Eurhizococcus brasiliensis) (Schuck et al., 1993; Rosier \& Losso, 1997; Instituto de Planejamento e Economia Agrícola de Santa Catarina, 2001). Em virtude da ocorrência de tais viroses, foram realizados trabalhos de seleção, propagação in vitro, produção e certificação de plantas matrizes e mudas (Schuck et al., 1993; Silva et al., 1997; Moreira, 2000; Silva, 2002).

Como resultado, Santa Catarina desenvolveu uma viticultura tecnificada e industrial, impulsionada pela forte demanda de matéria-prima (uva para vinhos e sucos) e pelo aumento no consumo de vinhos tintos de melhor qualidade, o que tem tornado o mercado atrativo e gerado grande procura de plantas matrizes e mudas certificadas para uso em novos plantios (Protas et al., 2002; Silva, 2002).

Durante as fases da cultura in vitro, as plantas crescem sob condições especiais de redução das trocas gasosas, alta umidade do ar, baixa intensidade luminosa e uso de açúcar como fonte de energia. Estas condições podem causar inibição da fotossíntese, estômatos anormais, maior acúmulo de reservas ou biomassa, dificultando a micropropagação e a aclimatização, proporcionando perdas elevadas de plantas na transferência para as condições ex vitro (Sciutti \& Morini, 1993; Desjardins, 1995; Pospísilová et al., 1999).

No caso da videira, as técnicas de cultura in vitro têm demonstrado grande potencial para a propagação de plantas (Roubelakis-Angelakis \& Zivanovitc, 1991; Torregrosa \& Bouquet, 1995; Silva et al., 1997; Biasi et al., 1998). Além da propagação, é possível avaliar e caracterizar genótipos tomando-se por base parâmetros morfofisiológicos do crescimento, como a utilização do $\mathrm{CO}_{2}$ e produção de biomassa (Galzy \& Compan, 1992; Silva et al., 1996; Fila et al., 1998; Moreira, 2000), teor de clorofila (Restagno et al., 1995; Amâncio et al., 1999; Carvalho et al., 2001), características estomáticas (Silva \& Doazan, 1995; Silva et al., 1996; Moreira, 2000), transpiração e potencial hídrico das folhas (Fila et al., 1998; Iacono \& Martinelli, 1998) que são parâmetros fundamentais para a micropropagação e aclimatização de plantas.
O objetivo deste trabalho foi estabelecer e multiplicar in vitro seis porta-enxertos de videira de interesse comercial e avaliar parâmetros morfofisiológicos fundamentais à micropropagação e aclimatização.

\section{Material e Métodos}

Plantas matrizes, provenientes da Epagri, Videira, SC, da Universidade de Davis, Califórnia, EUA, e do Istituto Agrario di San Michele all'Adige, Trento, Itália, foram mantidas em casa de vegetação no Departamento de Fitotecnia da Universidade Federal de Santa Catarina, Florianópolis, SC.

Foram selecionados os porta-enxertos de videira de maior interesse agronômico para o Estado de Santa Catarina, sendo: VR043-43 (Vitis vinifera $\mathrm{x}$ Vitis rotundifolia) e VR039-16 (Vitis vinifera $\mathrm{x}$ Vitis rotundifolia) resistentes à fusariose e tolerantes à margarodes; Paulsen 1103 (Vitis berlandieri x Vitis rupestris) e R110 (Vitis berlandieri $\mathrm{x}$ Vitis rupestris) com alta resistência à fusariose; $\mathrm{SO} 4$ (Vitis berlandieri $\mathrm{x}$ Vitis riparia) e Kober 5BB (Vitis berlandieri x Vitis riparia) ambos sensíveis à fusariose.

A partir de plantas matrizes, foram retirados explantes, ou seja, segmentos nodais contendo gemas axilares, que foram imersos por 10 min em água destilada + detergente Tween 20 (20 gotas/L); 3 min em álcool 70\% em agitação; em câmara de fluxo laminar, permaneceram por 15 min em hipoclorito de sódio (1,5\%) + Tween 20 (20 gotas/L) e foram submetidos a três lavagens com água destilada. Os explantes foram estabelecidos e multiplicados, conforme método proposto por Galzy (1969), em meio de cultura DSD1 (Silva \& Doazan, 1995) com 20,0 g/L de sacarose e 5,5 g/L de ágar-ágar. $\mathrm{O}$ pH do meio de cultura foi ajustado para 6,4 antes da autoclavagem.

As culturas foram mantidas em sala de crescimento com temperatura de $25 \pm 1^{\circ} \mathrm{C}$, fotoperíodo de 16 horas, intensidade luminosa de $40-45 \mu \mathrm{mol} / \mathrm{m}^{2} / \mathrm{s}$ e umidade relativa de $60 \%$ a $70 \%$.

As plantas com 60 dias de cultura in vitro foram avaliadas quanto ao número de folhas e de raízes, comprimento do caule e de raízes, medidos com um paquímetro manual. Na análise da área foliar, as folhas foram escaneadas e as imagens foram avaliadas com o auxílio do software IDRISI Versão 2.0. Em seguida, determinou-se a biomassa seca com a pesagem das partes da planta que permaneceram em estufa por 48 horas a $70^{\circ} \mathrm{C}$. Cada tratamento constituiu-se de seis plantas por genótipo. 
A concentração de clorofila total foi determinada em folhas sadias e completas das plantas in vitro e aclimatizadas em casa de vegetação. Amostras de $100 \mathrm{mg}$ de folhas frescas foram incubadas em banho-maria com $7 \mathrm{~mL}$ de dimetilsulfóxido (DMSO) por duas horas a $65^{\circ} \mathrm{C}$, semmaceração. Após filtragem, o volume total foi corrigido para $10 \mathrm{~mL}$. Os valores foram obtidos por meio de espectrofotometria (SHIMADZU UV-1203) considerando-se a densidade ótica medida a $645 \mathrm{~nm}$ e 663 nm, conforme Hiscox \& Israelstam (1979). No cálculo de clorofila "Chl a" e "Chl b" foram utilizadas as fórmulas de Arnon (1949): Chl a $=[0,0127 \times(663 \mathrm{~nm})-0,00269 \times(645 \mathrm{~nm})] \mathrm{e}$ Chl b $=[0,0229 \times(645 \mathrm{~nm})-0,00468 \times(663 \mathrm{~nm})]$. A clorofila total foi a soma da "Chl a" e "Chl b". De cada tratamento foram analisadas seis amostras de folhas por genótipo.

Na determinação da densidade estomática, número de estômatos por $\mathrm{mm}^{2}$ de superfície foliar, foram selecionadas as folhas sadias da porção média dos ramos das plantas aclimatizadas em casa de vegetação. Nas plantas in vitro, utilizou-se a quinta folha aberta a partir do ápice. Amostras de $100 \mathrm{mg}$ foram tratadas com DMSO (dimetilsulfóxido) por duas horas em banho-maria a $65^{\circ} \mathrm{C}$, e em seguida fixadas sobre lâminas microscópicas. Com o auxílio de um microscópio ótico (OLYMPUS BX4, ocular WH10 X 22, 400x), foram avaliadas dez folhas com dez repetições por folha, em um total de 100 observações por genótipo, em ocular especial com $0,16 \mathrm{~mm}^{2}$, o que permitiu o cálculo direto da densidade estomática.

No processo de aclimatização, as plantas da cultura in vitro dos seis genótipos foram podadas conservando três a quatro folhas basais, e as raízes lavadas e podadas a 2-3 cm de comprimento. O plantio foi feito em bandejas contendo Plantmax ${ }^{\circledR}$, colocadas em caixas de plástico cobertas com vidro (atmosfera saturada) e transferidas para sala de aclimatização. Cada unidade experimental foi constituída de 20 plantas e cinco repetições. Dados de porcentagem de sobrevivência foram coletados em 30 dias de cultivo ex vitro.

Em todos os experimentos, utilizou-se o delineamento inteiramente casualizado. Os dados foram submetidos à análise de variância e as médias comparadas pelo teste de Student-Newman-Keuls (SNK) a 5\% de probabilidade com auxílio do programa STATIGRAPHICS 7.0 (Sokal \& Rohfl, 1995).

\section{Resultados e Discussão}

A porcentagem média de explantes introduzidos in vitro foi de $42 \%$ dos seis genótipos testados. As melhores porcentagens de sobrevivência foram observadas nos porta-enxertos VR039-16, R110 e SO4 (50\%), seguido de Kober 5BB (40\%),
Paulsen 1103 (35\%) e VR043-43 (25\%). As taxas de sobrevivência podem ser consideradas baixas, se comparadas a outros métodos de introdução in vitro de videira (Silva et al., 1997; Biasi et al., 1998).

Os maiores números médios de folhas por planta foram obtidos com o porta-enxerto Kober 5BB (7,5 folhas/brotos), que só não diferiu do Paulsen 1103 (7,2 folhas/brotos) (Tabela 1). O número de raízes por planta variou de 1,5 a 3,2 e não houve diferenças significativas entre os porta-enxertos. Estudos morfofisiológicos ligados a estas características também foram relatados em cinco híbridos VR (V. vinifera $\mathrm{V}$. rotundifolia) por Torregrosa \& Bouquet (1995); na seleção in vitro dos porta-enxertos de videira Gravesac e Fercal, por Silva \& Doazan (1995); no cultivo em meio líquido de quatro genótipos de videira, por Zlenko et al. (1995). De acordo com estes trabalhos, os resultados, geralmente, estão relacionados com a composição do meio de cultura e com o genótipo testado.

Em relação ao comprimento do caule, ocorreu a formação de dois grupos (Tabela 1). Um grupo composto de quatro porta-enxertos originários da espécie $V$. berlandieri cruzada com $V$. rupestris (Paulsen 1103 e $\mathrm{R} 110$ ) e V. riparia (SO4 e Kober 5BB), que foi superior ao grupo formado por dois porta-enxertos originários da espécie $V$. vinifera cruzada com $V$. rotundifolia. No primeiro grupo, o Paulsen 1103, com crescimento in vitro de $6,2 \mathrm{~cm}$ de altura, não diferiu do R110, do SO4 e do Kober 5BB. No segundo grupo, o VR039-16 apresentou menor crescimento caulinar $(2,7 \mathrm{~cm})$, dife-

Tabela 1. Parâmetros morfológicos de porta-enxertos de videira após 60 dias de cultura in vitro em meio de cultura DSD $1^{(1)}$.

\begin{tabular}{|c|c|c|c|c|c|}
\hline \multirow[t]{2}{*}{ Porta-enxerto } & \multicolumn{2}{|c|}{ Número } & \multicolumn{2}{|c|}{$\begin{array}{c}\text { Comprimento } \\
(\mathrm{cm})\end{array}$} & \multirow[t]{2}{*}{$\begin{array}{c}\text { Área foliar } \\
\left(\mathrm{cm}^{2}\right)\end{array}$} \\
\hline & Folh & $\mathrm{B}$ & Caule & Raízes & \\
\hline & $5,8 \pm_{0}$ & $6 \mathrm{a}$ & $3,5 \pm 0,5 \mathrm{c}$ &, $5 \mathrm{~b}$ & \\
\hline VR & & & $2,7 \pm^{ \pm} 0,5 \mathrm{~d}$ & & \\
\hline Pat & & $3,2 \pm 2,0 \mathrm{a}$ & $6,2 \pm 0,4 \mathrm{a}$ & $10,5 \pm 2,0 \mathrm{a}$ & \\
\hline R1 & $6,4 \pm 0,7 \mathrm{bc}$ & $2,3 \pm 0,9 a$ & $5,6 \pm 0,6 a b$ & $10,5 \pm 2,6 a$ & $9,7 \pm 1,8 b$ \\
\hline & $6,1 \pm_{0,8 b c}$ & $3,0 \pm 1,4 \mathrm{a}$ & $5,6 \pm_{0,6 \mathrm{ab}}$ & $9,0^{ \pm} 3,1 \mathrm{ab}$ & b $12,8 \pm 2,2 b$ \\
\hline Kober 5BB & $7,5 \pm 0.5 \mathrm{a}$ & $3,0 \pm 1,2 \mathrm{a}$ & $5,2 \pm 0,5 \mathrm{~b}$ & $6,5 \pm 3,6 b$ & $9,5 \pm 1,1$ \\
\hline
\end{tabular}

${ }^{(1)}$ Médias seguidas de mesma letra na coluna não diferem entre si pelo teste Student-Newman-Keuls (SNK) a 5\% de probabilidade; os valores das variáveis são apresentados como média+desvio-padrão; DSD1: $20 \mathrm{~g} / \mathrm{L}$ de sacarose, 5,5 g/L de ágar-ágar e pH de 6,4 antes da autoclavagem (Silva \& Doazan, 1995). 
rindo do VR043-43. As variedades Paulsen 1103 e R110 apresentaram o maior crescimento radicular $(10,5 \mathrm{~cm})$. O efeito das condições in vitro, principalmente do meio de cultura, sobre o crescimento e enraizamento de videira in vitro foram relatados por Roubelakis-Angelakis \& Zivanovitc (1991), Galzy \& Compan (1992), Zlenko et al. (1995) e Moreira (2000). Os resultados de comprimento do caule estão entre os limites de 1,5 e 7,0 cm definidos por Torregrosa \& Bouquet (1995) com cinco genótipos híbridos de VR (V. vinifera $\mathrm{x}$ V. rotundifolia) e o porta-enxerto Fercal. Estes são superiores aos encontrados por Roubelakis-Angelakis \& Zivanovitc (1991) e Biasi et al. (1998) e inferiores aos encontrados por Galzy \& Compan (1992) e Moreira (2000) com diferentes variedades de videira.

A maior área foliar média foi observada em Paulsen $1103\left(18,1 \mathrm{~cm}^{2}\right)$, a qual, possivelmente, influenciou os demais parâmetros de crescimento (Tabela 1). A análise da área foliar também foi relacionada com o crescimento de Rubus sp. (Desjardins, 1995) e Limuniun sp. (Lian et al., 2002). Silva \& Doazan (1995) e Silva et al. (1996) obtiveram resultados similares aos observados neste trabalho com os porta-enxertos de videira Gravesac e VR043-43. Estes autores observaram alta correlação entre a superfície foliar e a biomassa total, e destacaram a importância destes parâmetros na fotossíntese e na propagação de plantas in vitro.

Quanto à produção de biomassa das plantas in vitro, os porta-enxertos Paulsen 1103 (34,8 mg) e SO4 (35,6 mg) apresentaram o maior acúmulo de matéria seca; o R110 não diferiu do Kober 5BB e do VR039-16 e, por último, o VR043-43 não diferiu do Kober 5BB e do VR039-16 (Tabela 2). Com relação à alocação de biomassa aos diferentes órgãos da planta in vitro, em todos os genótipos, o maior acúmulo de matéria seca ocorreu nas folhas, seguido pelo caule e, em menor quantidade, nas raízes. Entretanto, o VR043-43 priorizou a alocação de biomassa na raiz em relação ao caule.

A produção de biomassa total também foi parâmetro de avaliação de crescimento e alocação de reservas in vitro de porta-enxertos de videira (Silva \& Doazan, 1995; Silva et al., 1996; Amâncio et al., 1999; Moreira, 2000), e do efeito do açúcar na produção de biomassa de plantas in vitro do porta-enxerto 41B (Fila et al., 1998) e de Vitis vinifera cv. Touriga Nacional (Carvalho et al., 2001). Segundo estes autores, a produção de biomassa total é o parâmetro mais confiável para avaliar o crescimento e a multiplicação in vitro.

A biomassa retida nas folhas das culturas in vitro foi superior à retida nos demais órgãos avaliados, representando, em média, 52,9\% da matéria seca total, em todos os genótipos testados (Tabela 2). Estes resultados estão de acordo com as observações de Fila et al. (1998) e Moreira (2000). Os porta-enxertos VR043-43, VR039-16 e Paulsen 1103 apresentaram uma alocação de biomassa foliar mais acentuada, maior que $50 \%$ da matéria seca total, enquanto nos porta-enxertos R110, SO4 e Kober 5BB, ocorreu um certo equilíbrio na alocação da matéria seca entre caule e raiz.

O teor de clorofila variou entre os genótipos e entre os ambientes de cultura in vitro e ex vitro (Tabela 3). Os porta-enxertos VR039-16 e Paulsen 1103 apresentaram teores superiores in vitro, enquanto nos porta-enxertos VR043-43, R110, SO4 e Kober 5BB, os maiores valores de clorofila foram obtidos em casa de vegetação.

Nas condições in vitro, o teor de clorofila total variou de 0,70 a $1,48 \mathrm{mg} / \mathrm{g}$ de matéria fresca. Os porta-enxertos VR039-16, Paulsen 1103 e VR043-43 foram superiores aos demais, com valores próximos a $1,50 \mathrm{mg} / \mathrm{g}$. O SO4 e o Kober 5BB apresentaram resultados intermediários de $1,10 \mathrm{e}$ $1,02 \mathrm{mg} / \mathrm{g}$ e não diferiram entre si. Nas plantas aclimatizadas em casa de vegetação, o VR043-43 apresentou o maior teor de clorofila $(2,76 \mathrm{mg} / \mathrm{g})$,

Tabela 2. Produção e distribuição de biomassa de porta-enxertos de videira após 60 dias de cultura in vitro em meio de cultura DSD1 ${ }^{(1)}$.

\begin{tabular}{llrrr}
\hline \multirow{2}{*}{ Porta-enxerto } & \multicolumn{4}{c}{ Matéria seca (mg) } \\
\cline { 2 - 5 } & \multicolumn{1}{c}{ Raiz } & \multicolumn{1}{c}{ Caule } & \multicolumn{1}{c}{ Folha } & Total \\
\hline VR043-43 & $3,7 \pm 0,8 \mathrm{bc}$ & $3,5 \pm 1,4 \mathrm{c}$ & $15,8 \pm 0,7 \mathrm{a}$ & $23,0 \pm 2,9 \mathrm{c}$ \\
VR039-16 & $2,7 \pm 1,0 \mathrm{c}$ & $6,2 \pm 1,0 \mathrm{~b}$ & $15,0^{ \pm} 1,3 \mathrm{a}$ & $23,8 \pm 3,3 \mathrm{bc}$ \\
Paulsen 1103 & $5,7 \pm 2,3 \mathrm{ab}$ & $10,9 \pm 2,8 \mathrm{a}$ & $18,2 \pm 3,9 \mathrm{a}$ & $34,8 \pm 9,1 \mathrm{a}$ \\
R110 & $7,6^{ \pm} 2,9 \mathrm{a}$ & $8,4 \pm 2,1 \mathrm{~b}$ & $12,8^{ \pm} 1,9 \mathrm{~b}$ & $28,8 \pm 6,8 \mathrm{~b}$ \\
SO4 & $6,5 \pm 2,0 \mathrm{ab}$ & $13,0 \pm 1,9 \mathrm{a}$ & $16,1 \pm 2,0 \mathrm{a}$ & $35,6 \pm 5,9 \mathrm{a}$ \\
Kober5BB & $6,4^{ \pm} 2,8 \mathrm{ab}$ & $8,1 \pm 2,0 \mathrm{~b}$ & $11,5 \pm 1,3 \mathrm{~b}$ & $26,0 \pm 6,0 \mathrm{bc}$ \\
\hline \multicolumn{5}{c}{} \\
(1) Médias seguidas de mesma letra, na coluna, não diferem entre si pelo \\
teste Student-Newman-Keuls (SNK) a 5\% de probabilidade; os valores \\
das variáveis são apresentados como média \pm desvio padrão; DSD1: \\
20 g/L de sacarose, 5,5 g/L de ágar-ágar e pH de 6,4 antes da autoclavagem \\
(Silva \& Doazan, 1995).
\end{tabular}


diferindo dos demais genótipos, enquanto o Paulsen $1103(0,86 \mathrm{mg} / \mathrm{g})$ foi inferior a todos os porta-enxertos.

As plantas in vitro normalmente apresentam redução nos teores de clorofila, quando comparadas às plantas aclimatizadas (Dejardins, 1995; Amâncio et al., 1999; Pospísilová et al., 1999). Isto foi verificado na maioria dos genótipos, exceto nos porta-enxertos VR039-16 e Paulsen 1103 que, possivelmente, ainda estão em processo de adaptação às novas condições de ambiente em casa de vegetação.

Os teores de clorofila total das plantas in vitro são similares aos relatados por Restagno et al. (1995), Amâncio et al. (1999) e Moreira (2000). Segundo Restagno et al. (1995), os valores observados são considerados altos, demonstrando que os teores de clorofila não seriam limitantes ao funcionamento do aparato fotossintético in vitro. Desta forma, as condições impostas pela cultura in vitro parecem não afetar a síntese e conteúdo de clorofila na videira in vitro (Moreira, 2000).

$\mathrm{Na}$ cultura in vitro, os maiores números de estômatos por $\mathrm{mm}^{2}$ foram observados nos porta-enxertos VR039-16 (216,4 estômatos $\left./ \mathrm{mm}^{2}\right)$ e VR043-43 (205,3 estômatos/mm²). Valores intermediários de 153,8; 152,9 e 148,6 estômatos $/ \mathrm{mm}^{2}$ foram constatados nos porta-enxertos SO4, R110 e Paulsen 1103, respectivamente (Tabela 3). Nas plantas aclimatizadas em casa de vegetação, o porta-enxerto VR039-16 apresentou densidade estomática $\left(179,4 / \mathrm{mm}^{2}\right)$ superior à dos demais porta-enxertos.

Os estômatos em plantas in vitro estão relacionados com a capacidade de fotossíntese e o processo de aclimatização, uma vez que estes exercem importante papel na regulação das trocas gasosas e perda de água pela transpiração (Iacono \& Martinelli, 1998; Moreira, 2000). A densidade estomática in vitro foi superior na maioria dos porta-enxertos, exceto no Kober 5BB. Maior número de estômatos em plantas in vitro é citado em diferentes espécies (Pospísilová et al., 1999). Em relação à videira, Moreira (2000) verificou decréscimo de 31,6\% na densidade estomática em plantas após aclimatização do porta-enxerto Paulsen 1103. Os valores obtidos em relação à densidade estomática estão dentro dos limites normais no gênero Vitis, tanto para plantas de cultura in vitro como para as cultivadas em casa de vegetação (Silva \& Doazan, 1995; Moreira, 2000).

Os estômatos dos porta-enxertos de videira in vitro mostraram aspectos normais, com forma elíptica, sem deformação, a maioria abertos, mas com presença de outros semi-abertos e fechados. Estas características podem indicar uma funcionalidade similar aos estômatos de outras espécies in vitro (Schoch et al., 1989; Sciutti \& Morini, 1993). No porta-enxerto de videira '41B', os estômatos in vitro apresentaram respostas à luz e ao $\mathrm{CO}_{2}$, indicando mecanismos de funcionalidade (Fila et al., 1998). Os resultados observados são diferentes dos de Santamaria \& Kerstiens (1994), Desjardins (1995) e Pospísilová et al. (1999), os quais relataram que os estômatos in vitro são malformados, reduzidos em número e inábeis para a função, tornando as plantas mais suscetíveis à desidratação na fase de aclimatização.

Os porta-enxertos Kober 5BB e Paulsen 1103 apresentaram taxa de $95 \%$ de sobrevivência na aclimatização, demonstrando diferenças estatísticas apenas em relação aos porta-enxertos R110 (84\%) e SO4 $(85 \%)$ (Tabela 3$)$.

Tabela 3. Teor de clorofila total, número de estômatos e taxa de sobrevivência na aclimatização de porta-enxertos de videira $^{(1)}$.

\begin{tabular}{|c|c|c|c|c|c|c|}
\hline Ambiente $^{(2)}$ & VR043-43 & VR039-16 & Paulsen 1103 & R110 & $\mathrm{SO} 4$ & Kober 5BB \\
\hline & \multicolumn{6}{|c|}{ Clorofila total (mg/g de matéria fresca) } \\
\hline In vitro & $1,45 \pm_{0,10 b}$ & $1,48 \pm 0,13 b$ & $1,46^{ \pm} 0,10 \mathrm{~b}$ & $0,70 \pm 0,08 \mathrm{f}$ & $1,10^{ \pm} 0,16 \mathrm{~cd}$ & $1,02 \pm 0,11 \mathrm{~d}$ \\
\hline Ex vitro & $2,76^{ \pm} 0,15 \mathrm{a}$ & $1,00 \pm 0,07 \mathrm{~d}$ & $0,86 \pm 0,05 \mathrm{e}$ & $1,00 \pm 0,07 \mathrm{~d}$ & $1,22 \pm 0,12 \mathrm{c}$ & $1,38^{ \pm} 0,03 \mathrm{~b}$ \\
\hline \multicolumn{7}{|c|}{ Densidade estomática (número de estômatos $/ \mathrm{mm}^{2}$ ) } \\
\hline In vitro & $205,3^{ \pm} 6,2 \mathrm{a}$ & $216,4 \pm 6,2 \mathrm{a}$ & $148,6 \pm 3,6 c$ & $152,9 \pm 3,2 \mathrm{c}$ & $153,8{ }^{ \pm} 4,5 \mathrm{c}$ & $130,8 \pm 3,0 \mathrm{~d}$ \\
\hline Ex vitro & $152.9 \pm 3.1 \mathrm{c}$ & $179.4 \pm 2.1 \mathrm{~h}$ & $132.9 \pm 3.4 \mathrm{~d}$ & $1276 \pm 3.0 \mathrm{~d}$ & $192 \pm 2.9 \mathrm{~d}$ & $144.4 \pm 3.2 c$ \\
\hline \multicolumn{7}{|c|}{ Sobrevivência (\%) } \\
\hline
\end{tabular}

(1)Para cada variável, as médias seguidas de mesma letra não diferem entre si pelo teste Student-Newman-Keuls (SNK) a 5\% de probabilidade; os valores das variáveis são apresentados como média \pm desvio-padrão. ${ }^{(2)}$ In vitro: laboratório; ex vitro: casa de vegetação. 
Os resultados de $84 \%$ a $95 \%$ de plantas sobreviventes no processo de aclimatização indicam que o método usado foi apropriado na transferência de videira in vitro para as condições ex vitro. Esses valores são semelhantes aos de Silva et al. (1997), Biasi et al. (1998) e Moreira (2000). Essa alta taxa de sobrevivência verificada na aclimatização está possivelmente relacionada com o comportamento e o crescimento da videira in vitro, que dependem das trocas gasosas, funcionalidade de estômatos, aquisição precoce e diferenciação do aparato fotossintético, uso eficiente e controle da água, raízes ativas e normais (Silva et al., 1996; Fila et al., 1998; Iacono \& Martinelli, 1998; Amâncio et al., 1999; Moreira, 2000).

\section{Conclusões}

1. O estabelecimento in vitro e a micropropagação de porta-enxertos de videira podem ser realizados com microestacas de gemas axilares multiplicadas em meio de cultura DSD1.

2. A avaliação dos diferentes parâmetros morfofisiológicos em porta-enxertos de videira in vitro demonstra que a variabilidade genotípica se manifesta nesse ambiente, no crescimento, enraizamento e distribuição da biomassa.

3. Os teores de clorofila e a densidade de estômatos dos porta-enxertos de videira in vitro são comparáveis aos observados em plantas ex vitro, indicando que estes não são limitantes para a multiplicação e aclimatização de videira.

4. O método usado na aclimatização de videira in vitro é eficaz, sendo esta influenciada positivamente pelas características morfofisiológicas normais das plantas in vitro, proporcionando $90,3 \%$ de plantas sobreviventes.

\section{Referências}

AMÂNCIO, S.; REBORDÃO, J. P.; CHAVES, M. M Improvement of acclimatization of micropropagated grapevine: photosynthetic competence and carbon allocation. Plant Cell, Tissue and Organ Culture, Dordrecht, v. 58, p. 31-37, 1999.

ARNON, D. I. Cooper enzymes in isolated chloroplasts: polyphenoloxidases in Beta vulgaris. Plant Physiology, Rockville, v. 24, n. 1, p. 1-15, 1949.

BIASI, L. A.; PASSOS, I. R. S.; POMMER, C. V. Micropropagação do porta-enxerto de videira Jales. Pes- quisa Agropecuária Brasileira, Brasília, v. 33, n. 10, p. 1587-1594, out. 1998.

CARVALHO, L. C.; OSÓRIO, M. L.; CHAVES, M. M.; AMÂNCIO, S. Chlorophyll fluorescence as an indicator of photosynthetic functioning of in vitro grapevine and chestnut plantlets under ex vitro acclimatization. Plant Cell, Tissue and Organ Culture, Dordrecht, v. 67, p. 271280, 2001.

DESJARDINS, Y. Overview of factors influencing photosynthesis of micropropaged plantlets and their effect on acclimatization. In: CARRE, F.; CHAGVARDIEFF, P. (Ed.). Ecophysiology and photosynthetic in vitro cultures. Saint-Paul-lez-Durance: Centre d'études de Cadarache, 1995. p. 145-160.

FILA, G.; GHASHGHAIE, J.; HOARAU, J.; CORNIC, G. Photosynthesis, leaf conductance and water relations of in vitro cultured grapevine rootstock in relation to acclimatization. Physiologia Plantarum, Copenhagen, v. 102, p. 411-418, 1998.

GALZY, R. Remarques sur la croissance de Vitis rupestris cultivée in vitro sur diffèrents milieux nutritifs. Vitis, Geneva, v. 8, p. 191-205, 1969.

GALZY, R.; COMPAN, D. Remarks on mixotrophic and autotrophic carbon nutrition of Vitis plantlets cultured in vitro. Plant Cell, Tissue and Organ Culture, Dordrecht, v. 31, p. 239-244, 1992.

HISCOX, J. D.; ISRAELSTAM, G. F. A method for the extraction of chlorophyll from leaf tissue without maceration. Canadian Journal of Botany, Guelph, v. 57, p. 1332-1334, 1979.

IACONO, F.; MARTINELLI, L. $\mathrm{CO}_{2}$ assimilation and transpiration balance in species of genus Vitis cultivated in vivo and in vitro: estimation of stomatal and cuticular transpiration in vitro. Journal International des Sciences de la Vigne et du Vin, Bordeaux, v. 32, n. 2, p. 91-97, 1998.

INSTITUTO DE PLANEJAMENTO E ECONOMIA AGRÍCOLA DE SANTA CATARINA (Florianópolis, SC). Síntese anual da agricultura de Santa Catarina. Florianópolis, 2001. 248 p.

LIAN, M. L.; MURTHY, H. N.; PAEK, K. Y. Culture method and photosynthetic photon flux affect photosynthesis, growth and survival of Limonium 'Misty Blue' in vitro. Scientia Horticulturae, Amsterdam, v. 95, p. 239-249, 2002.

MOREIRA, F. M. Avaliação morfofisiológica e bioquímica do porta-enxerto de videira 'Paulsen 1103' in vitro. 2000. 91 f. Dissertação (Mestrado em Recursos Genéticos Vegetais) - Universidade Federal de Santa Catarina, Florianópolis, 2000. 
POSPÍSILOVÁ, J.; TICHÁ, I.; KADLECEK, P.; HAISEL, D.; PLZÁKOVÁ, S. Acclimatization of micropropagated to ex vitro conditions. Biologia Plantarum, Prague, v. 42, n. 4, p. 481-497, 1999.

PROTAS, J. F. de S.; CAMARGO, U. A.; MELO, L. M. R. de. A viticultura brasileira: realidade e perspectivas. In: VITICULTURA e enologia: atualizando conceitos. Caldas: Epamig, 2002. p. 17-32.

RESTAGNO, M.; SCHUBERT, A.; GRIBAUDO, I. Rubisco activity in micropropagated plantlets. In: CARRE, F.; CHAGVARDIEFF, P. (Ed.). Ecophysiology and photosynthetic in vitro cultures. Saint-Paul-lez-Durance: Centre d'études de Cadarache, 1995. p. 205-206.

ROSIER, J. P.; LOSSO, M. Cadeias produtivas do Estado de Santa Catarina: vitivinicultura. Florianópolis: Epagri, 1997. 41 p.

ROUBELAKIS-ANGELAKIS, K. A.; ZIVANOVITC, $\mathrm{S}$. B. A new culture medium for in vitro rhizogenesis of grapevine (Vitis spp.) genotypes. HortScience,Alexandria, v. 26, n. 12 , p. $1551-1553,1991$.

SANTAMARIA, J. M.; KERSTIENS, G. The lack of control of water loss in micropropagated plants is not related to poor cuticle developement. Physiologia Plantarum, Copenhagen, v. 91, p. 191-195, 1994.

SCHOCH, P. G.; LEFEVRE, B.; TEISSON, C.; GANRY, $\mathrm{J}$. Photosynthèse et respiration de bananier in vitro. Photosynthetica, Praha, v. 23, p. 113-118, 1989.

SCHUCK, E.; ANDRADE, E. R. de; GALLOTTI, G. J. M.; DAL BÓ, M. A. Novas alternativas na busca de soluções para o controle do declínio da videira. Revista Agropecuária Catarinense, Florianópolis, v. 6, n. 4, p. 48-50, 1993.
SCIUTTI, R.; MORINI, S. Effect of relative humidity in in vitro culture on some growth characteristics of a plum rootstock during shoot proliferation and rooting and on plantlet survival. Advances in Horticultural Science, Firenze, v. 7, p. 153-156, 1993.

SILVA, A. L. da. Programa de certificação de mudas de videira em Santa Catarina. In: VITICULTURA e enologia: atualizando conceitos. Caldas: Epamig, 2002. p. 215-231.

SILVA, A. L. da; DOAZAN, J. P. Une méthode d'irradiation aux rayons gamma appliquée à des portegreffes de vigne in vitro. Journal International des Sciences de la Vigne et du Vin, Bordeaux, v. 29, n. 1, p. 1-9, 1995.

SILVA, A. L. da; HARISCAIN, P.; OLLAT, N.; DOAZAN, J. P. Estimations de la capacité photoautotrophique de vitroplants de porte-greffe de vigne 'Gravesac': mise au point d'un système de mesure de la photosynthèse nette de vitroplants. Vitis, Geneva, v. 35, n. 2, p. 73-78, 1996.

SILVA, A. L. da; SCHUCK, E.; HARISCAIN-LAFITTE, P.; PARIZZOTTO, A. Cultura in vitro do porta-enxerto de videira var. 043-43 resistente a fusariose. In: SIMPÓSIO BRASILEIRO DE MELHORAMENTO DE FRUTÍFERAS, 1., 1997, Jaboticabal. Anais... Jaboticabal: Unesp, 1997. p. 51-53.

SOKAL, R. R.; ROHLF, F. J. Biometry. $3^{\text {rd }}$ ed. New York: W. H. Freeman, 1995. 881 p.

TORREGROSA, L.; BOUQUET, A. In vitro propagation of Vitis x Muscadinia hybrids by microcuttings or axillary budding. Vitis, Geneva, v. 34, n. 4, p. 237-238, 1995.

ZLENKO, V. A.; TROSHIN, L. P.; KOTIKOV, I. V. An optimized medium for clonal micropropagation of grapevine. Vitis, Geneva, v. 34, n. 2, p. 125-126, 1995. 